\title{
EVALUATION OF DevR ANTIGEN (MSMEG_5244) AS A PUTATIVE BIOMARKER FOR THE SERODIAGNOSIS OF PERSISTANT Mycobacterium tuberculosis
}

\author{
RADHAMAHENDRAN S. ${ }^{1,2}$, MALATHI R. ${ }^{*}$, JAYARAMAN G. ${ }^{1}$ AND SAMBANTHAM $\mathbf{} .{ }^{1}$ \\ 1Department of Genetics, University of Madras, Dr. ALM PG IBMS, Sekkizhar Campus, Chennai- 600 113, TN, India. \\ 2Department of Bioinformatics, Vels University, Chennai- 600 117, TN, India. \\ *Corresponding Author: Email-r_malathi@hotmail.com
}

Received: April 04, 2013; Accepted: April 15, 2013

\begin{abstract}
Tuberculosis (TB) is a major health problem in the developing world. 9 million new cases of TB and three million deaths are reported every year around the globe. The management of tuberculosis in the regions of developing countries urgently needs an efficient diagnostic test. DevR (also called DosR) is essential for promoting long-term survival of Mycobacterium tuberculosis under low oxygen conditions in a dormant state and may be responsible for latent tuberculosis in one-third of the world's population.

The similarity in sequences of DevR in Mycobacterium smegmatis and Mycobacterium tuberculosis has been already proved and hence Mycobacterium smegmatis is used as a model in present study for studying and evaluating the immunogenic properties of antigen DevR. Elimination of tuberculosis (TB) largely depends upon definitive rapid diagnosis and treatment. Widely used diagnostic methods do not qualify for use in a developing country due to lack of either desired accuracy and cost. In the present study ELISA was used to evaluate the diagnostic potential of an immuno-dominant antigen DevR from 36 BCG vaccinated and 12 non-vaccinated TB patients. 48 samples were collected from healthy control subjects. We have evaluated the diagnosis of tuberculosis, based on detection of anti-lgG antibodies in the TB patient's sera. The mean IgG antibody levels in sera of both $B C G$ vaccinated $(n=36)$ and non-vaccinated $(n=12)$ patients with tuberculosis were significantly higher compared to the healthy donors $(p<0.05)$. The results suggest that DevR could be possible candidate biomarker for effective use in the serodiagnosis of persistant tuberculosis infections.
\end{abstract}

Keywords- DevR, Serodiagnosis, ELISA, Tuberculosis, Mycobacterium smegmatis

Citation: RadhaMahendran S., et al. (2013) Evaluation of DevR Antigen (MSMEG_5244) As a Putative Biomarker for the Serodiagnosis of Persistant Mycobacterium tuberculosis. International Journal of Molecular Biology, ISSN: 0976-0482 \& E-ISSN: 0976-0490, Volume 4, Issue 1, pp.-81-86.

Copyright: Copyright@2013 RadhaMahendran S., et al. This is an open-access article distributed under the terms of the Creative Commons Attribution License, which permits unrestricted use, distribution and reproduction in any medium, provided the original author and source are credited.

\section{Introduction}

Tuberculosis (TB) has placed a heavy burden on the global community for Centuries, earning such morbid nicknames as, 'The White Plague' and 'the Captain of the Men of Death' [1]. The causative agent, Mycobacterium tuberculosis (MTB), kills about 2 million people annually making it a leading cause of infectious death worldwide $[2,3]$. Current estimates place the number of people latently infected with MTB at nearly 2 billion, or one-third of the Earth's population $[3,4]$. Eradicating this enormous reservoir of latently infected carriers is complicated by several factors, including the availability, cost, and length of drug therapy required for successful treatment of latent TB.

The discovery of genes that play key roles in mycobacterial persistence has paved the way towards identifying novel targets unique to persistent organisms. Two-component regulatory systems belong to this class of novel targets. [5-7]. Two-component systems are majorly involved in sensing and responding to changing environments in bacteria [8]. DevR is one of the best characterized transcriptional regulators of MTB. It is a typical two-domain response regulator of the NarL subfamily [9] and its $\mathrm{N}$-terminal domain that contains a phosphorylation site, Asp54, is connected to the C-terminal DNA binding domain (DevRC) by a linker sequence [10-13]. The target genes of the DevR regulon are predicted to contain one, two or more putative DevR binding sites (Dev boxes) in their upstream regions [14]. In bacteria, two-component response regulator systems are an important means by which a variety of environmental signals are transduced into a phenotypic response. These systems typically consist of a membrane-bound sensor kinase and soluble response regulator that is activated by a histidine-aspartate phosphorelay to bind to upstream of specific genes and alter their expression [15].

In Mycobacterium tuberculosis the DevR-DevS two-component system, along with sensor kinase DosT, plays a key role in its adaptation to hypoxia and to other signals likely to prevail in- vivo, such as nitric oxide, carbon monoxide, and vitamin C [16-22]. During bacterial adaptation to hypoxia and other stress signals, DevR response regulator mediates the induction of $\sim 48$ genes that make up the DevR dormancy regulon [23]. The Two-component systems (TCSs) are typically composed of a membrane-located sensor with histidine kinase activity and a cytoplasmic transcriptional regulator. 
Generally, stimuli detected by these systems are transformed into a cellular signal by autophosphorylation of the sensor proteins at a conserved histidine residue. The phosphorylated histidine of these sensor proteins is the source for phosphorylation of an aspartic acid residue in the so-called 'receiver domain' of the transcription factor. Phosphorylation of the regulatory proteins induces a conformational change which alters their DNA-binding properties. A small number of TCSs are characterized by a complex phosphorelay between two histidine and two aspartic acid residues present in four signalling domains, which can either be independent proteins or be integrated into multidomain TCS proteins in various combinations [24]. Already in previous studies it has been reported that DevR is a stationaryphase regulator required for adaptation to oxygen starvation and resistance to heat stress in $M$. smegmatis [25].

Thus DevR is proposed to be an attractive target for the development of inhibitors against dormant organisms [26-29] and for developing vaccine against persistent organisms [30-32]. The present study aims to over express the recombinant protein (DevR) in $E$. coli BL21 (DE3) and purify it to determine the immunological reactiveness by testing sera from TB patients and healthy donors of south Indian population. This may help to identify and develop a novel anti-tuberculosis vaccine with higher efficiency than BCG by genetic engineering.

\section{Materials and Methods \\ Materials}

Mycobacterium smegmatis was obtained from Tuberculosis research center, Chennai, India. Escherichia coli strains XL10 gold and BL21 (DE3) were obtained from Stratagene, USA. Plasmid pRSET-A was obtained from Invitrogen, USA. T4 DNA Ligase, Sacl and $\mathrm{Kpnl}$ were obtained from Fermentas, Thermo scientific, Inc. Spin Clean Chelating IDA Excellose column $(1 \mathrm{mg} / \mathrm{mL})$ from Mbiotech, South Korea. Anti-Human IgG conjugated with HRP, TMB/ $\mathrm{H}_{2} \mathrm{O}_{2}$ were obtained from Merck, USA. All other chemicals were of molecular biology grade or higher.

\section{Culturing of Mycobacterium smegmatis and E. coli}

Mycobacterium smegmatis was inoculated in LJ slants incubated at $37^{\circ} \mathrm{C}$. E. coli XL10 gold harboring pRSET-A was grown in LB broth with ampicillin $(100 \mu \mathrm{g} / \mathrm{mL})$ overnight at $37^{\circ} \mathrm{C}$, in a shaker incubator (250 rpm). E. coli BL21 (DE3) and XL10 gold were grown in LB broth overnight at $37^{\circ} \mathrm{C}$, in a shaker incubator.

\section{pRSET-A Plasmid Isolation, Genomic DNA Isolation, PCR Am- plification and Cloning of DevR Protein of Mycobacterium smegmatis}

The pRSET-A plasmid was isolated from E. coli using SIGMA plasmid miniprep Kit. Genomic DNA of M. smegmatis was isolated by Phenol/Chloroform method and checked for purity by UV spectrophotometer and electrophoresis in agarose gel. The DevR gene is amplified using the primers,

\section{DevR-F-(5'-GATTCGAGCTCATGATCAGGGTTTTTCTGGT-3') and}

DevR-R-(5'-GTACCGGTACCCTAGTTGCGCCGGTCCAGTTTG-3').

PCR was performed for 34 cycles of denaturation at $94^{\circ} \mathrm{C}$ for $30 \mathrm{~s}$, annealing at $55^{\circ} \mathrm{C}$ for $30 \mathrm{~s}$, extension at $72^{\circ} \mathrm{C}$ for $30 \mathrm{~s}$, followed by final extension for $5 \mathrm{~min}$ at $72^{\circ} \mathrm{C}$. The PCR product and pRSET-A plasmid were subjected to restriction digestion using Sacl and Kpnl. Then the PCR product and plasmid were ligated using T4 DNA Ligase. The ligated plasmids were transformed to $E$. coli $\mathrm{BL} 21$ (DE3) using calcium chloride mediated heat shock method as de- scribed by Chung and Miller with minor modifications [33]. The recombinants were selected by growing the transformed $E$. coli cells in ampicillin containing LB broth and confirmed by insert release from the recombinant plasmids.

\section{DNA Sequence Analysis}

The orientation of recombinant clone DevR: PRSETA, were commercially sequenced [Applied Biosystems $(P)$ Ltd; Bangalore, India] to confirm inframe ligation. Oligonucleotide $\mathrm{T7}$ forward and pRSET$A$ reverse primers were used for sequencing. The amplified products were preceded for Cycle sequencing PCR reactions. Extended products were precipitated and purified by using $3 \mathrm{M}$ sodium acetate and ethanol purification method and the samples were denatured at $94^{\circ} \mathrm{C}$ for 5 minutes after adding hidiformamide and the sample plate was linked to 373-48 capillary array equipment, ABI (Applied Biosystems).

\section{Expression and Purification of DevR Protein in E. coli BL21 (DE3)}

The expression of DevR was induced by 1.5nM IsoPropyl-1-Thio- $\beta$ D- Galactopyranoside (IPTG) in mid-log phase $\left(\mathrm{OD}_{600} \mathrm{~nm}\right.$ of 0.6 $0.7)$ at $25^{\circ} \mathrm{C}$ for 5 hours. The expressed recombinant protein was isolated and purified by capturing the DevR using Spin Clean Chelating IDA Excellose column (1 $\mathrm{mg} / \mathrm{mL})$. The quality of the expressed and purified DevR was checked by Tricine-SDS-PAGE followed by staining with Coomassie brilliant blue R-250 stain.

\section{Immunoscreening of the Recombinant Protein Antigen in TB Patients}

\section{Study Population}

After informed consent, $5 \mathrm{~mL}$ of venous blood samples were obtained from 36 BCG vaccinated and 12 non-vaccinated TB patients (20-60yrs old patients from Govt. Hospital of Thoracic Medicine, Tambaram sanatorium, Chennai and Govt. Hospitals at Erode and Salem, Tamilnadu, India). The sera were separated by standard procedure and the decomplementation was done at $56^{\circ} \mathrm{C}$ for 30 minutes. Finally the sera were stored at $-20^{\circ} \mathrm{C}$ with appropriate labeling. A total of 48 samples were collected from healthy control subjects.

\section{ELISA}

The recombinant protein was screened for antigenic properties. Enzyme linked immunosorbant assay (ELISA) was done to detect the $\operatorname{lgG}$ antibodies to the purified protein in the serum of both $M$. tuberculosis infected patients and healthy control subjects. For ELISA, 96-well polystyrene microtiter plates were coated with antigen (DevR) at $1 \mu \mathrm{g} / \mathrm{mL}(0.1 \mathrm{~mL}$ per well) in carbonate-bicarbonate buffer (PH 9.0) overnight at $4^{\circ} \mathrm{C}$. The plates were washed thrice with washing buffer. Plates were blocked with phosphate buffered saline (pH 7.4) containing $1 \% \mathrm{BSA}$ for $2 \mathrm{Hrs}$. at $37^{\circ} \mathrm{C}$ and washed extensively with PBS. Serum samples were diluted at 1:500 in sample dilution buffer and $0.1 \mathrm{~mL}$ of diluted serum was added to antigencoated wells in duplicate and incubated for $30 \mathrm{~min}$ at room temperature. Plates were washed extensively with PBS-T and then incubated for 30 min with $0.1 \mathrm{~mL}$ of 1:10,000 diluted goat anti-human lgG conjugated with horseradish peroxidase (HRP) per well. Plates were washed with PBS-T and $0.1 \mathrm{~mL}$ of $\mathrm{TMB} / \mathrm{H}_{2} \mathrm{O}_{2}$ was added to each well and incubated for 20 minutes. After the addition of $0.1 \mathrm{~mL}$ of $1 \mathrm{~N} \mathrm{H}_{2} \mathrm{SO}_{4}$ to stop the reaction, the optical density at $450 \mathrm{~nm}$ (OD 450) was measured with an automatic microplate reader (Versa Mex, Molecular devices). 


\section{Statistical Methods}

The ELISA results are expressed as percentages wherever appropriate. The means and standard deviations (SD) were calculated for the sera of uninfected healthy donors $(n=48)$ and the cut off for positive response was calculated as greater than the mean plus 3 $\mathrm{SD}$, and for high level responses, as the mean plus $6 \mathrm{SD}$. The mean of control group ( $\mathrm{N}=48$ ) was compared with the mean of TB patients (BCG vaccinated and non-vaccinated) group $(n=48)$ for the significance by using students T-test [34].

\section{Results}

\section{Cloning of DevR Gene and Recombinant Selection}

The genomic DNA was isolated from M. smegmatis [Fig-1] and PCR amplification of DevR gene was obtained with no non-specific amplification [Fig-2]. The ligated recombinant plasmid with DevR gene was successfully screened [Fig-3]. The insert was released by digesting with Sacl and Kpnl [Fig-4] and sequenced to find the DevR gene is in-frame with the plasmid [Fig-5]. The recombinant plasmids were over expressed by IPTG induction for 4 hours [Fig-6] and the DevR protein product $(30 \mathrm{KDa})$ was purified using Spin Clean Chelating IDA Excellose column [Fig-7].

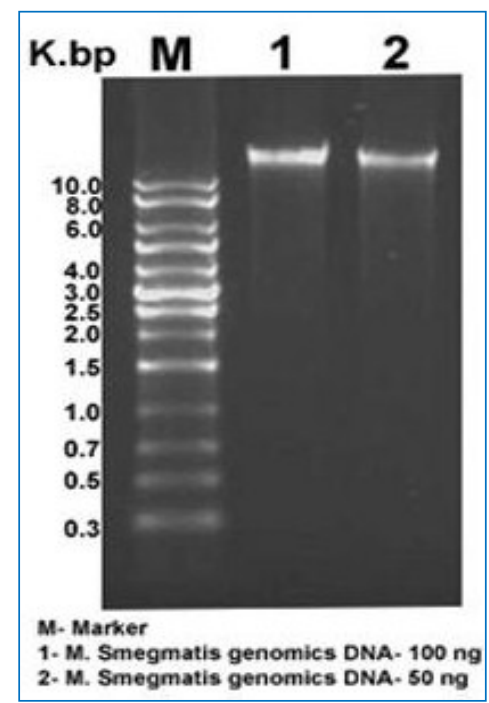

Fig. 1- Genomic DNA Isolated from M. smegmatis

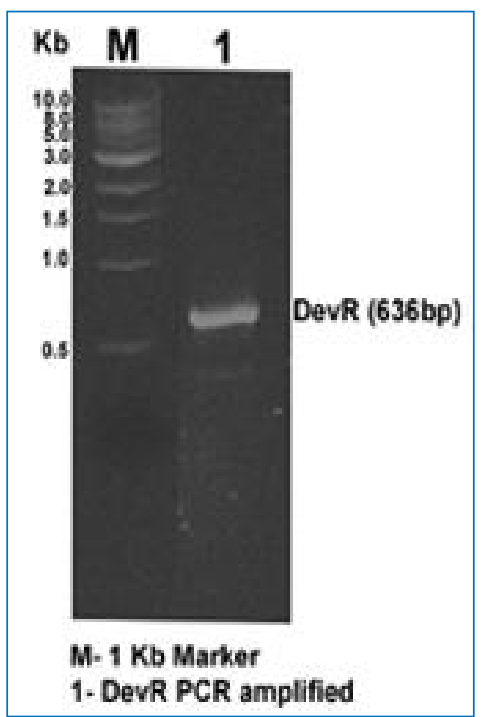

Fig. 2- PCR amplification of DEVR gene

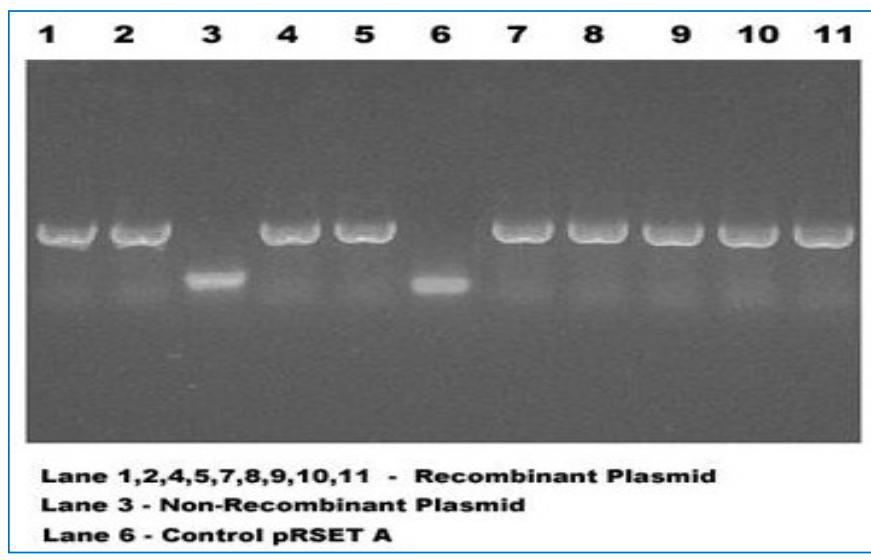

Fig. 3- Recombinant plasmid with DEVR gene selection

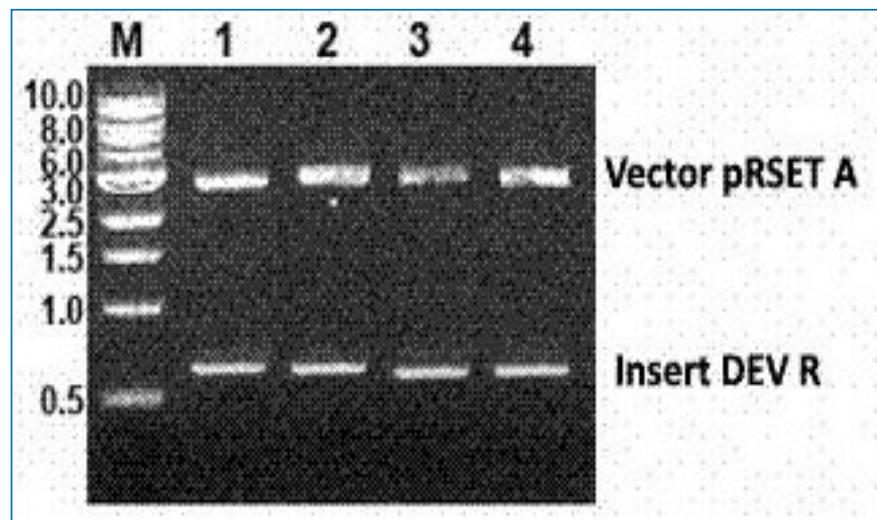

Fig. 4- Insert released by double digestion with $\mathrm{Kpnl}$ and Sacl

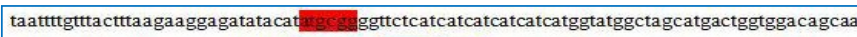
atgggtcgggatctgtacgacgatgacgataaggatcc agct ATGATCAGGGTTTTTCTGGTCGACGAC CACGAGGTGGTGCGCCGCGGGCTCATCGACCTGCTGAGCGCCGATCCCGAACTG GACGTCATCGGCGAGGCCGATTCGGTGTCGCAGGCGCTCGCGCGCATCCCCGCG GCGCAGCCGGATGTCGCGGTGCTCGACGTGCGGCTGCCCGACGGCAACGGCATC GAGCTGTGCCGGGACCTGTTGTCGCACATGCCGAATCTGCGCTGCCTGATGCTCA CGTCGTTCACCTCCGACGAAGCGATGCTCGACGCGATCCTCGCGGGCGCGAGCG GATACGTGGTCAAGGACATCAAGGGCATGGAACTCGCGCAGGCCATCAAGGACG TCGGCGCGGGCAAGTCCCTGCTGGACAACCGCGCGGCCACCGCGCTGATGTCCA AACTGCGCGGCGACGCCGAACGCTCCGATCCGCTCTCGGGCCTCACCCAGCAGG AGCGTGTGCTGCTCGACCTGCTGGGAGAGGGCCTGACCAACAAACAGATCGCGG CGCGCATGTTCCTGGCCGAGAAGACCGTCAAGAACTACGTGTCGAGGCTCCTGG CGAAGCTCGGCATGGAGCGTCGCACGCAGGCCGCGGTGTTCGCGTCCAAACTGG ACCGGCGCAACTAGgetaccatggaattcgaagcttgatccggctgctaacaaagcccgaaaagaagctgagttggctg ctgccaccgctgagcaataactaaca

IPolyhistidine region IRestriction Site (Sac I); - Dev R start Codon; |Restriction site (Kpn I)

Fig. 5- Cloned DVER gene sequence to pRSET - A plasmid

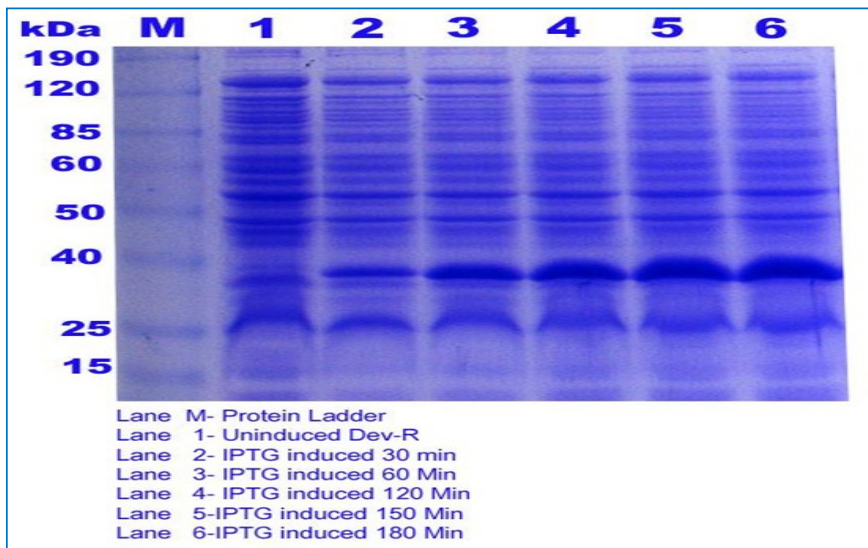

Fig. 6- SDS page analysis of total protein content of IPTG induced E. coli with recombinant plasmid 


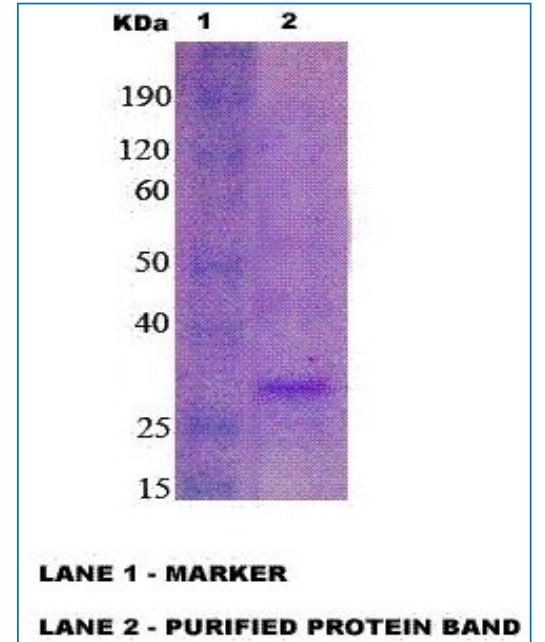

Fig. 7- Purified DEVR protein

\section{Measurement of IgG Antibody to Mycobacterial Recombinant Antigen by ELISA}

In the present study, immunoreactivity of DevR to $\lg G$ antibody in the sera from TB patients was detected by ELISA. The study populations (20-60yrs old) were grouped based on the BCG vaccination. The serum IgG antibody titer values against Mycobacterium smegmatis recombinant protein antigen DevR were measured from the healthy donors (negative control) group of 48 individuals. The mean and standard deviation (SD) were calculated from the sera of healthy control and subjects $(n=48)$. The mean plus $3 S D$ of the healthy donors was used as the cut off point for positive response and high level positive response. The cut off response for positive response and high level positive response for mycobacterial recombinant antigen were shown in [Table-1]. In the healthy donors group, recombinant protein DevR was found to be below the cut off value. Thus, the cutoff values were sufficient for determination of a positive response. The comparison of TB patients with the cutoff value is shown in the [Fig-8].

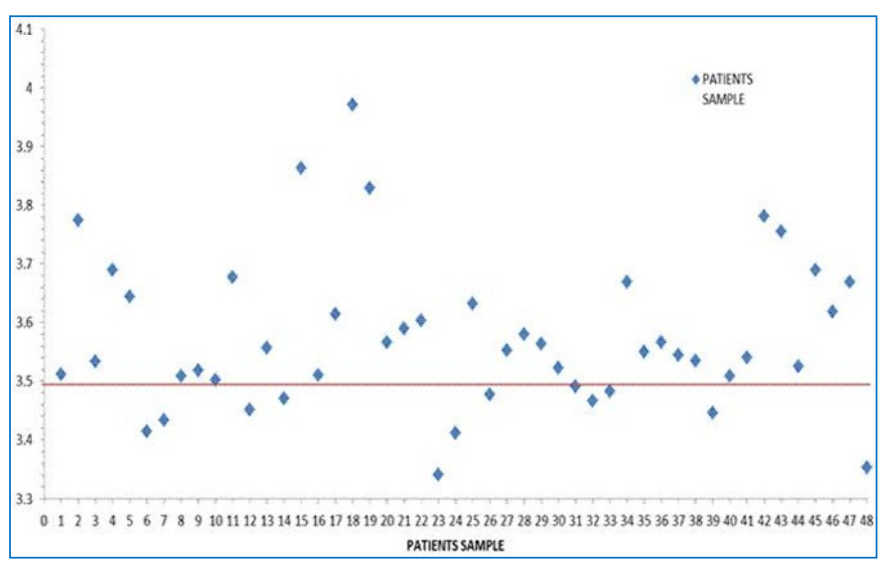

Fig. 8- Evaluation of $\lg G$ in the sera from BCG vaccinated and nonvaccinated pulmonary TB Patients using Mycobacterium smegmatis DEVR purified recombinant antigen by ELISA

Table 1- Cutoff values for DevR recombinant Mycobacterial protein antigen. (Based on the response to the sera of healthy donors)

\begin{tabular}{|c|c|c|c|c|c|c|}
\hline Antigen & $\begin{array}{l}\text { Mean OD } \\
\text { at 450nm }\end{array}$ & SD & 3SD & 6SD & $\begin{array}{l}\text { Cutoff values (Mean } \\
\text { OD at } 450 \mathrm{~nm}+3 \mathrm{SD} \text { of } \\
\text { Healthy donors) }\end{array}$ & $\begin{array}{l}\text { Cutoff values (Mean } \\
\text { OD at } 450 \mathrm{~nm}+6 \mathrm{SD} \text { of } \\
\text { Healthy donors) }\end{array}$ \\
\hline DevR & 3.231 & 0.089 & 0.2673 & 0.5346 & 3.498 & 3.765 \\
\hline
\end{tabular}

The mean $\lg G$ antibody levels in sera of both $B C G$ vaccinated $(n=36)$ and non- vaccinated $(n=12)$ patients with tuberculosis were significantly higher compared to the healthy donors in [Table-2]. The comparison of mean OD value of healthy controls with BCG vaccinated and non-vaccinated TB patients using ELISA and the statistical significance are summarized in [Table-3].

Table 2- Positive IgG immune response in the sera of TB patients to Mycobacterium smegmatis DevR recombinant antigen by ELISA (Based on cutoff values: Mean OD at 450nm + 3SD of the healthy donors)

\begin{tabular}{|c|c|c|c|}
\hline \multirow{3}{*}{$\begin{array}{l}\text { Mycobacterium } \\
\text { smegmatis } \\
\text { DevR } \\
\text { recombinant } \\
\text { antigen }\end{array}$} & \multicolumn{3}{|c|}{ Status of TB patients } \\
\hline & $\begin{array}{l}\text { BCG Vaccinated } \\
\text { Pulmonary TB } \\
\text { patients }(n=36)\end{array}$ & $\begin{array}{l}\text { Non BCG Vaccinated } \\
\text { Pulmonary } \\
\text { TB patients ( } n=12)\end{array}$ & $\begin{array}{c}\text { Both BCG vaccinated and } \\
\text { non-vaccinated Pulmonary } \\
\text { TB patients ( } n=48 \text { ) }\end{array}$ \\
\hline & \multicolumn{2}{|c|}{$\%$ of reactivity } & $\%$ of total reactivity \\
\hline DevR & $72.22 \%(26)$ & $83.33 \%(10)$ & $75 \%(36)$ \\
\hline
\end{tabular}

Table 3- IgG Immuno-reactivity of recombinant Mycobacterium smegmatis DevR antigen with sera of Healthy donors, BCG vaccinated TB patients and Non-vaccinated TB patients by ELISA

\begin{tabular}{|c|c|c|c|c|}
\hline \multirow{2}{*}{$\begin{array}{l}\text { Mycobacterium } \\
\text { smegmatis } \\
\text { DevR antigen }\end{array}$} & $\begin{array}{l}\text { Healthy donors } \\
\quad(n=48)\end{array}$ & $\begin{array}{l}\text { BCG vaccinated TB } \\
\text { patients ( } n=36)\end{array}$ & \multicolumn{2}{|c|}{$\begin{array}{c}\text { Non-vaccinated TB } \\
\text { patients }(n=12)\end{array}$} \\
\hline & Mean OD Standard & & & \\
\hline & & & & \\
\hline
\end{tabular}

\section{Discussion}

Tuberculosis remains one of the dreaded global infectious diseases. Identification of antigens and determination of their effect in eliciting the immune response are the most essential areas of TB research. A rapid, accurate and convenient diagnostic test is highly needed for the control of TB. To improve the diagnosis of TB, different diagnostic techniques have been investigated in recent years. The conventional methods of diagnosis including culture, microscopy and radiological methods have major limitations. Several serological assays like interferon-y assay have been used. These immune based tests for the detection of antibodies have the inability to distinguish from latent TB infection and exposure to nontuberculous Mycobacteria. Hence highly immunogenic antigens of Mycobacterium should be identified and a more detailed immunological analysis should be carried out to compare and evaluate their immunogenicity. The present study was designed to evaluate the efficacy of antigen DevR (MSMEG_5244) in serological diagnostic assays by determining the immunological reactivity of this protein. The protein encoding ORF was cloned, sequenced, expressed in $E$. coli and the recombinant protein was purified.

In bacteria, Two-Component Systems (TCS) have been widely used signal transduction devices which are engaged in a multitude of gene regulatory systems that respond to changing growth conditions. Many pathogenic bacteria encounter different microenvironments during their infectious cycle and their ability to efficiently adapt to different niches inside and outside of their host organisms is frequently mediated by TCSs, which can, therefore, be considered as an essential prerequisite for their pathogenicity. Although significant progress has been made in the elucidation of basic principles of the signal transduction process itself, in many pathogens the contribution of TCS to bacterial virulence is insufficiently recognized.

Owing to their versatility in sensing diverse intracellular and extracellular signals and their variable modular architecture, TCSs are convenient devices for the regulation of the expression of virulence properties. Despite the detailed knowledge about the phosphoryla- 
tion-based signal transduction mechanism itself, surprisingly little information is available about the molecular basis for its contribution to bacterial virulence. Future research should be aimed at understanding the targets of TCS mediated regulation, and the regulatory networks into which the TCSs are integrated to control the expression of such a multifarious phenotype as bacterial virulence [35-37].

The search for structurally unique antibiotics that inhibit new molecular targets has led researchers to prokaryotic two-component systems. Two-component systems are attractive for several reasons [38]. First of all, they are widespread in bacteria and, so far, absent in mammals. Therefore, general HK (Histidine kinase) or RR (Response regulators) inhibitors could potentially be broadspectrum antibiotics. Alternatively, by targeting specific HKs or RRs, selective inhibition may be achieved. The problem is that most twocomponent Systems are nonessential. However, there is interdependence not only among the proteins in these systems, but among the systems themselves. Cessation or slowing down of these intracellular networks may be a way to affect a cellular shutdown. Perhaps the most attractive reason for targeting two-component systems is that they are used by pathogenic bacteria to control the expression of virulence factors required for infectivity. Thus DevR could serve as a potential target for antimicrobial therapy.

In search for rapid and cost-effective diagnostic methods for TB, immunodiagnosis is considered an attractive option, which uses the specific humoral and cellular immune responses of the host to infer the presence of infection or disease. Recently, the antigen-specific ex vivo induction of interferon gamma (IFN- $\gamma$ ) had been used to detect infection with $M$. tuberculosis. However, the IFN- $\gamma$ release assay could not differentiate the latent tuberculosis infection and active tuberculosis efficiently and cannot be recommended for the diagnosis of tuberculosis in developing countries, as large proportions of the populations in such countries are likely to harbor latent infection with $M$. tuberculosis [39-41]. Historically speaking, serology for the diagnosis of TB has been explored since 1898, when crude cell preparations containing carbohydrates, lipids, and proteins from $M$. tuberculosis or M. bovis BCG were used as antigen preparations showing high sensitivity but low specificity [42]. Modern developments in the purification of antigens, generation of monoclonal antibodies and chromatographic techniques have led to a considerable improvement in specificity [43-49]. Serology has additional advantages in situations when the patient is unable to produce adequate sputum or sputum smear results are negative and TB is extra pulmonary.

Dowdy, et. al. [50] used a decision-analysis model that suggested that novel diagnostic tests have the potential to be cost-effective tools in TB control. They argued that "to produce a cost-effective tool for public health, the quest for new TB diagnostics should focus on high specificity, affordability and sensitivity for cases missed by existing diagnostic standards.

Data are accumulating that DevR response genes are induced during infections [51-55]. Careful dissection of the DevR response should help to establish whether it plays a role in TB latency in vivo and may facilitate a more focused approach to the discovery of new MTB targets for drug and vaccine development. DevR gene was PCR amplified from $M$. smegmatis genome. The PCR amplicon was cloned in pRSETA vector and transformed into $E$. coli XL10 gold. The cloned Mycobacterium smegmatis DevR ORFs was in frame with the sequences of ATG translation initiation codon, polyhistidine tag and the enterokinase cleavage recognition sequence. This was confirmed by DNA sequencing. The cloned ORF was expressed in E. coli BL21 (DE3) to produce recombinant protein and purified. The typical yield of purified DevR was about $\sim 5 \mathrm{mg} / 100 \mathrm{~mL}$ culture each.

ELISA was carried out to measure serological reactivity of Mycobacterium smegmatis DevR purified recombinant protein antigen. The serum IgG antibodies against these proteins were measured from healthy donors (negative control, group of 48 individuals) and TB patients $(n=48)$. The mean and standard deviation were calculated from the healthy donors. Comparatively, the mean $\lg G$ antibody levels in the sera of both BCG vaccinated $(n=36)$ and nonvaccinated $(n=12)$ patients with tuberculosis were appreciably higher than the healthy donors $(p<0.05)$. The above findings presented here suggest that DevR ( $M$. smegmatis) could be excellent diagnostic marker and very good candidate for vaccine against tuberculosis. Improved serodiagnostic test for TB can be developed only by rational design of carefully selected antigen covering broad spectrum of antibodies. Use of additional sero-reactive antigens of $M y-$ cobacterium tuberculosis will result in the detection of specific antibodies in almost all patients with active TB. To obtain high diagnostic specificity and accuracy, ideal candidates of serologically active antigens specific for Mycobacterium tuberculosis complex should be selected. The new generation of immunodiagnostic assays using immunodominant antigen could be a milestone in the diagnosis of tuberculosis and in the control of TB.

In conclusion, the recombinant protein DevR of Mycobacterium smegmatis was found to be immunodominant with apparent diagnostic potential. A large scale evaluation of this recombinant Mycobacterial protein in different geographic locations of India/Asia/ Africa will definitely help to develop serodiagnostic tests. Identification of more such immunogenic antigens of Mycobacterium tuberculosis in various populations will assist in the development of novel vaccine against Tuberculosis.

\section{References}

[1] Dock W. (1946) Am. Rev. Tuberc., 53, 297-305.

[2] Bloom B.R., and Small P.M. (1998) N. Engl. J. Med., 338, 677678.

[3] Dye C., Scheele S., Dolin P., Pathania V. and Raviglione M.C. (1999) J. Am. Med. Assoc., 282, 677-686.

[4] Enarson D.A. and Murray J.F. (1996) Tuberculosis, 55-75.

[5] Macielag M.J., Goldschmidt R. (2000) Expert Opin. Investig. Drugs, 9, 2351-2369.

[6] Stephenson K., Hoch J.A. (2002) Curr. Opin. Pharmacol., 2, 507-512.

[7] Tyagi J.S., Sharma D. (2004) Curr. Sci., 86, 93-102.

[8] Barrett J.F., Hoch J.A. (1998) Antimicrobial Agents and Chemotherapy, 42, 1529-1536.

[9] Dasgupta N., Kapur V., Singh K.K., Das T.K., Sachdeva S., et al. (2000) Tuber Lung Dis., 80, 141-159.

[10]Roberts D.M., Liao R.P., Wisedchaisri G., Hol W.G., Sherman D.R. (2004) J. Biol. Chem., 279, 23082-23087.

[11]Saini D.K., Malhotra V., Dey D., Pant N., Das T.K., et al. (2004) Microbiology, 150, 865-875.

[12]Wisedchaisri G., Wu M., Rice A.E., Roberts D.M., Sherman D.R., et al. (2005) J. Mol. Biol., 354, 630-641. 
[13]Wisedchaisri G., Wu M., Sherman D.R., Hol W.G. (2008) J. Mol. Biol., 378, 227-242.

[14]Park H.D., Guinn K.M., Harrell M.I., Liao R., Voskuil M.I., et al. (2003) Mol. Microbiol., 48, 833-843.

[15]Hoch J.A., Keith Stephenson and Yasuchika Yamaguchi (2000) The Journal of Biological Chemistry, 275, 38900-38904

[16]Lamichhane G. (2010) Trends Mol. Med., 17, 25-33.

[17]Murphy D.J. and Brown J.R. (2007) BMC Infect. Dis., 7, 84.

[18]Saini D.K., et al. (2004) Microbiology, 150, 865-875.

[19]Vohra R., Gupta M., Chaturvedi R. and Singh Y. (2006) Antiinfect. Drug Discov., 1, 95-106.

[20]Park H.D., et al. (2003) Mol. Microbiol. 48, 833-843.

[21]Shiloh M.U., Manzanillo P. and Cox J.S. (2008) Cell Host Microbe, 3, 323-330.

[22]Taneja N.K., Dhingra S., Mittal A., Naresh M. and Tyagi J.S. (2010) PLoS One, 5, e10860.

[23]Park H.D., Guinn K.M., Harrell M.I., Liao R., Voskuil M. I., Tompa M., Schoolnik G.K., Sherman D.R. (2003) Mol. Microbiol., 48, 833-843.

[24]West A.H., Stock A.M. (2001) Trends Biochem. Sci., 26, 369376.

[25]O'Toole R., Smeulders M.J., Blokpoel M.C., Kay E.J., Lougheed K., Williams H.D. (2003) J. Bacteriol., 185(5), 1543-54.

[26]Dasgupta N., et al. (2000) Tuber. Lung Dis., 80, 141-159.

[27]Kumar A., Toledo J.C., Patel R.P., Lancaster J.R. and Steyn A.J. (2007) Proc. Natl. Acad. Sci., 104, 11568-11573.

[28]Kumar A., et al. (2008) J. Biol. Chem., 283, 18032-18039.

[29]Majumdar S.D., et al. (2010) PLoS One, 5, e9448.

[30]Murphy D.J., Brown J.R. (2007) BMC Infect. Dis., 7, 84.

[31]Saini D.K., Tyagi J.S. (2005) J. Biomol. Screening, 10, 215-224.

[32]Wisedchaisri G., Wu M., Rice A.E., Roberts D.M., Sherman D.R., Hol W.G. (2005) J. Mol. Biol., 354, 630-641.

[33]Chung and Miller (1988) Nucleic Acid Research, 16, 3580.

[34]Moran, et al (2001) FEMS Microbiol. Lett., 198(1), 31-6.

[35]Matsushita M., Janda K.D. (2002) Bioorg. Med. Chem., 10, 855867.

[36]Stephenson K., Hoch J.A. (2002) Curr. Opin. Pharmacol., 2, 507-512.

[37]Stephenson K., Hoch J.A. (2004) Curr. Med. Chem., 11, 765773.

[38]Stock A.M., Robinson V.L. and Goudreau P.N. (2000) Annu. Rev. Biochem., 69, 183-215.

[39]Sester M., Sotgiu G., Lange C. et al. (2011) European Respiratory Journal, 37, 1, 100-111.

[40]Chee C.B.E., Barkham T.M.S., KhinMar K.W., Gan S.H. and Wang Y.T. (2009) European Journal of Clinical Microbiology and Infectious Diseases, 28(6), 667-670.

[41]Janssens J.P., Roux-Lombard P., Perneger T., Metzger M., Vivien R. and Rochat T. (2007) European Respiratory Journal, 30(4), 722-727.

[42]Aloring S. (1898) “Comptes Rendus de l'Acad'emie des Sciences, 126, 1398-1400.
[43]Zhang H., Wang J., Lei J. et al. (2007) Clinical Microbiology and Infection, 13(2), 139-145.

[44]Khan N., Alam K., Nair S., Valluri K.J., Murthy R. and Mukhopadhyay S. (2008) Clinical and Vaccine Immunology, 15(6), 974 -980 .

[45]Aagaard R.C., Weldingh K. et al. (2008) Tuberculosis, 88(4), 335-343.

[46]Choudhary R.K., Mukhopadhyay S., Chakhaiyar P. et al., (2003) Infection and Immunity, 71(11), 6338-6343.

[47]Jackett P.S., Bothamley G.H., Batra H.V., Mistry A., Young D.B. and Ivanyi J. (1988) Journal of Clinical Microbiology, 26(11), 2313-2318.

[48]Brust B., Lecoufle M., Tuaillon E., et al. (2011) PLoS ONE, 6(9), Article ID e25078.

[49]Zhao J.W., Sun Z.Q., Yang H.G., et al. (2011) Annals of Microbiology, 61(2), 345-353.

[50]Dowdy D.W., O'Brien M.A., Bishai D. (2008) Int. J. Tuberc. Lung Dis., 12, 1021-9.

[51]Voskuil M.I., Schnappinger D., Harrell M.I., Visconti K.C., Dolganov G., Sherman D.R. and Schoolnik G.K. (2003) J. Exp. Med., 198, 705-713.

[52]Parish T., Smith D.A., Kendall S., Casali N., Bancroft G. J. and Stoker N.G. (2003) Infect. Immun., 71, 1134-1140.

[53]Fenhalls G., Stevens L., Moses L., Bezuidenhout J., Betts J. C., van Helden P., Lukey P.T. and Duncan K. (2002) Infect. Immun., 70, 6330-6338.

[54]Ohno H., Zhu G., Mohan V.P., Chu D., Kohno S., Jacobs W.R. and Chan J. (2003) Microbiol., 5, 637-648.

[55]Shi L., Jung Y.J., Tyagi S., Gennaro M.L. and North R.J. (2003) Proc. Natl. Acad. Sci., USA, 100, 241-246. 